\title{
Atypicality Scale
}

National Cancer Institute

\section{Source}

National Cancer Institute. Atypicality Scale. NCI Thesaurus. Code C121273.

A rating scale included in the Behavior Assessment System for Children that measures

mood swings, bizarre thought, subjective experiences associated with obsessive

compulsive disorder, and odd behaviors in the subject. 